\title{
Understanding vasovagal syncope: a role for sex and gender
}

\author{
Satish R. Raj ${ }^{1,2} \cdot$ Sofia B. Ahmed ${ }^{3} \cdot$ Robert S. Sheldon $^{1,3}$ \\ Received: 8 April 2020 / Accepted: 9 April 2020 / Published online: 16 April 2020 \\ (c) Springer-Verlag GmbH Germany, part of Springer Nature 2020
}

Vasovagal syncope (VVS) is a common and frequently distressing problem. About $40 \%$ of people faint at least once in their life, and at least $20 \%$ of adults faint more than once [1]. VVS affects all ages and both sexes. It is known that there are multiple pathophysiological mechanisms underlying vasovagal syncope, ranging from decreased cardiac venous return [2], active arteriolar vasodilation due to a loss of sympathetic tone, to differential catecholamine release [3]. To date, it has been difficult to show the clear benefits of pharmacological therapies for VVS in well-designed randomized clinical trials $[4,5]$. VVS has shown a strong familial clustering [6], but it has been difficult to show a strong genetic basis underlying VVS [7].

A recent genetic association study in VVS took a slightly different approach. Instead of just looking at the overall cohort of 160 participants, the investigators probed 12 distinct candidate genes by sex [8]. There was no significant association for nine of the 12 candidate genes. In the serotonin 5-HT1A receptor gene (HTR1A), the presence of a G allele was associated with syncope in male (GG $77 \%$ vs. CC 9\%) but not in female participants. The SLC6A4 gene for the serotonin reuptake transporter promoter $\mathrm{L}$ alleles were associated with decreased syncope in males, but increased syncope in females. LL males had a $25 \%$ likelihood of syncope, while LL females had a 75\% likelihood of syncope. The catecholamine O-methyltransferase gene (COMT) A allele was associated with decreased syncope in males $(15 \%$ vs. $50 \%$ ) but increased syncope in females ( $73 \%$ vs. $52 \%$ ).

Satish R. Raj

Satish.raj@ucalgary.ca

1 Department of Cardiac Sciences, Libin Cardiovascular Institute of Alberta, University of Calgary, GAC70 HRIC Building, 3280 Hospital Drive NW, Calgary, AB T2N 4Z6, Canada

2 Division of Clinical Pharmacology, Department of Medicine, Autonomic Dysfunction Center, Vanderbilt University Medical Center, Nashville, TN, USA

3 Department of Medicine, Libin Cardiovascular Institute of Alberta, University of Calgary, Calgary, AB, Canada
Importantly, these relationships might have been overlooked if only a global analysis had been performed.

In this issue of Clinical Autonomic Research, Ghariq and colleagues report their experience from their high-volume tilt testing laboratory [9]. Overall, the proportions of men and women with a positive tilt table test were not different when corrected for age. However, the difference became apparent when looking at tilt test provocation. Women were less likely than men to have a positive drug-free tilt table test (odds ratio 0.54 ), but were more likely to have a positive tilt table test in the setting of nitroglycerin provocation. These data suggest that there might be different sex-based pathophysiological substrates to positive tilt table testing in males and females. These insights would be missed in their entirety if sex-specific analyses were not planned and performed.

The importance of sex and gender in clinical research, and in understanding our clinical care, has become increasingly clear [10]. This has led to initiatives from national funding agencies to encourage (https://orwh.od.nih.gov/ sex-gender/sexgender-influences-health-and-disease), and in some cases dictate, sex- and gender-based analyses in clinical research (https://www.cihr-irsc-igh-isfh.ca/).

While the terms are often erroneously used interchangeably, sex and gender refer to distinct concepts. Sex refers to an objective biological component, defined by the genetic dotation since the time of conception, and manifesting in cellular, molecular, and hormonal differences. So far, sex cannot be changed. The concept of gender, however, is less clear but has gained prominence in the last decades. Gender identity is a subjective assessment of how an individual perceives and presents themselves; it has to do with the social, emotional, environmental, cultural, and behavioral factors that influence a person's self-identity. Gender identity can be very fluid; an individual could self-identify with one or multiple genders, which could also change over time. While the assessment of gender is evolving and can be challenging (e.g., there are currently more than 50 different terms to refer to different gender identities), a simple starting point would be to ask research participants about both their objective biological sex at birth (i.e., as indicated on their birth 
certificate), and also how they define themselves in terms of gender identity.

Aside from political correctness, this is relevant because gender roles could impact cardiovascular health. For instance, a feminine gender, independent of the objective biological sex, appears to be associated with an increased risk of recurrent acute coronary syndrome [11]. And a recent paper by Bernier and colleagues might point to differential effects of sex and gender in patients with syncope [12]. Using administrative data of patients presenting to hospital with syncope in Alberta, Canada, the investigators found that women had lower mortality rates than men. However, women were more likely to present to the emergency department than men. The survival advantage observed in women in this study likely reflects both biological differences between males and females, and gender-related social/emotional factors that resulted in earlier presentation for medical attention.

So, moving forward, it appears that collecting information on sex and gender in clinical research projects may provide interesting scientific information. Ideally, outcome data should be reported both in toto and also stratified by sex (for biological variables) and, if possible, for gender (for psychosocial or cultural variables).

Funding Supported in part by the National Institutes of Health grant UL1 TR000445, and by the Canadian Institutes of Health Research (CIHR; Ottawa, Canada) Grant MOP142426.

\section{Compliance with ethical standards}

Conflict of interest None.

\section{References}

1. Ganzeboom KS, Mairuhu G, Reitsma JB, Linzer M, Wieling W, Van Dijk N (2006) Lifetime cumulative incidence of syncope in the general population: a study of 549 Dutch subjects aged 35-60 years. J Cardiovasc Electrophysiol 17(11):1172-1176

2. Fu Q, Levine BD (2014) Pathophysiology of neurally mediated syncope: Role of cardiac output and total peripheral resistance. Auton Neurosci 184:24-26

3. Kohno R, Detloff BLS, Chen LY, Norby FL, Benditt DG (2019) Greater early epinephrine rise with head-up posture: a marker of increased syncope susceptibility in vasovagal fainters. J Cardiovasc Electrophysiol 30(3):289-296

4. Sheldon R, Raj SR, Rose MS, Morillo CA, Krahn AD, Medina E et al (2016) Fludrocortisone for the prevention of vasovagal syncope: a randomized placebo-controlled trial. J Am Coll Cardiol 68(1):1-9

5. Sheldon R, Connolly S, Rose S, Klingenheben T, Krahn A, Morillo C et al (2006) Prevention of syncope trial (POST): a randomized, placebo-controlled study of metoprolol in the prevention of vasovagal syncope. Circulation 113(9):1164-1170

6. Serletis A, Rose S, Sheldon AG, Sheldon RS (2006) Vasovagal syncope in medical students and their first-degree relatives. Eur Heart J 27(16):1965-1970

7. Klein KM, Berkovic SF (2014) Genetics of vasovagal syncope. Auton Neurosci 184:60-65

8. Sheldon RS, Rose MS, Ritchie D, Martens K, Maxey C, Jagers J et al (2019) Genetic association study in multigenerational kindreds with vasovagal syncope: evidence for involvement of sex-specific serotonin signaling. Circ Arrhythm Electrophysiol 12(1): $\mathrm{e} 006884$

9. Ghariq M, Thijs RD, Bek LM, van Zwet EW, Benditt DG, van Dijk JG (2020) A higher proportion of men than of women fainted in the phase without nitroglycerin in tilt-induced vasovagal syncope. Clin Auton Res. https://doi.org/10.1007/s10286-020-00666 -5(in Press)

10. Clayton JA, Tannenbaum C (2016) Reporting sex, gender, or both in clinical research? JAMA 316(18):1863-1864

11. Pelletier R, Khan NA, Cox J, Daskalopoulou SS, Eisenberg MJ, Bacon SL et al (2016) Sex versus gender-related characteristics: which predicts outcome after acute coronary syndrome in the young? J Am Coll Cardiol 67(2):127-135

12. Bernier R, Tran DT, Sheldon RS, Kaul P, Sandhu RK (2020) A population-based study evaluating sex differences in patients presenting to emergency departments with syncope. JACC Clin Electrophysiol 6(3):341-347 